\title{
Novel mechanisms underlying anti-polycystic ovary like syndrome effects of electroacupuncture in rats: suppressing SREBP1 to mitigate insulin resistance, mitochondrial dysfunction and oxidative stress
}

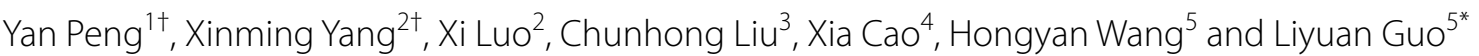

\begin{abstract}
Background: Acupuncture, a therapy of traditional Chinese medicine, is confirmed to exert the therapeutic action on polycystic ovary syndrome (PCOS). However, the detailed therapeutic mechanisms of acupuncture in PCOS remain ambiguous. In this study, we further investigated whether electroacupuncture (EA) alleviated PCOS-like symptoms in rats via regulating a metabolic regulator, sterol regulatory element binding protein-1 (SREBP1).

Methods: The PCOS-like rat model was built by hypodermic injection with dehydroepiandrosterone (DHEA). The rats were subjected to EA intervention (ST29 and SP6 acupuncture points) for 5 weeks. Primary granulosa cells were isolated from control and PCOS-like rats for evaluating insulin resistance, mitochondrial dysfunction and oxidative stress in vitro.

Results: The expression of SREBP1 was increased in PCOS-like rats, which was suppressed by EA treatment. In addition, lentivirus-mediated overexpression of SREBP1 restrained EA treatment-induced improvement in pathological changes, serum hormone levels and insulin resistance in rats. In addition, overexpression of SREBP1 repressed insulinstimulated phosphorylation of insulin receptor $\beta$ (IR) and AKT in primary granulosa cells. Moreover, upregulation of SREBP1 further exacerbated mitochondrial dysfunction and oxidative stress in granulosa cells isolated from PCOS-like rats. Mechanically, EA treatment suppressed SREBP1 expression through inducing the activation of AMP-activated protein kinase (AMPK) signaling pathway in PCOS-like rats.
\end{abstract}

Conclusion: EA intervention alleviated PCOS-like symptoms in rats via improving IR, mitochondrial dysfunction and oxidative stress through regulating SREBP1, a lipid metabolism regulator. Our findings illuminate the novel protective mechanisms of EA in the treatment of PCOS.

Keywords: Electroacupuncture, PCOS, SREBP1, AMPK, Insulin resistance

\footnotetext{
*Correspondence: guoliyuan80@163.com

${ }^{\dagger}$ Yan Peng and Xinming Yang contributed equally to this study.

${ }^{5}$ Department of Gynecological Oncology, Cancer Hospital of Harbin Medical University, Harbin 150081, People's Republic of China

Full list of author information is available at the end of the article
}

\section{Background}

Polycystic ovary syndrome (PCOS) is an endocrine disorder commonly seen in women of reproductive age, which is considered as the main reason for menstrual disorder and infertility [1]. It was reported that the prevalence rate of PCOS was $6-18 \%$ around the world [2]. Numerous studies have confirmed that insulin resistance may

(c) The Author(s) 2020. This article is licensed under a Creative Commons Attribution 4.0 International License, which permits use, sharing, adaptation, distribution and reproduction in any medium or format, as long as you give appropriate credit to the original author(s) and the source, provide a link to the Creative Commons licence, and indicate if changes were made. The images or other third party material in this article are included in the article's Creative Commons licence, unless indicated otherwise in a credit line to the material. If material is not included in the article's Creative Commons licence and your intended use is not permitted by statutory regulation or exceeds the permitted use, you will need to obtain permission directly from the copyright holder. To view a copy of this licence, visit http://creativeco mmons.org/licenses/by/4.0/. The Creative Commons Public Domain Dedication waiver (http://creativecommons.org/publicdomain/ zero/1.0/) applies to the data made available in this article, unless otherwise stated in a credit line to the data. 
frequently occur in PCOS patients and lead to hyperinsulinemia, which takes part in the pathogenic mechanisms of PCOS [3, 4]. Insulin is a kind of multifunctional hormone that is involved in the regulation of glucose, fat, and protein metabolism. Therefore, the insulin resistance in PCOS patients may increase the risk of developing type 2 diabetes mellitus, hypertension, and hyperlipemia $[5,6]$. Currently, there are limited available treatments for PCOS. Thus, exploring novel effective measure for PCOS and elucidating its mechanisms are urgently needed.

Previous studies indicated that the pharmacological and surgical therapies for PCOS may inevitably have side effects such as cardiovascular disease and multifetation $[7,8]$. However, electroacupuncture (EA) has been recognized as a safe treatment and contributes to restore reproductive endocrine function of PCOS [9-11]. But so far, the therapeutic mechanisms of EA in PCOS has not been clearly clarified.

Sterol regulatory element binding protein-1 (SREBP1) is a key gene of lipid metabolism regulation, and its level has been reported to be upregulated in PCOS patients [12]. Additionally, Shah et al. found that eicosapentaenoic acid alleviated PCOS via suppressing SREBP1 expression in rats [13]. It has also been suggested that SREBP1 plays crucial roles in modulating insulin resistance. For example, inhibition of SREBP1-mediated lipogenesis effectively improved diet-induced insulin resistance [14]. In addition, SREBP1 has been demonstrated to participate in palmitate acid-induced insulin resistance via regulating IRS-1 expression and insulin signaling pathway in skeletal muscle [15]. A previous study by Li et al. showed that EA intervention could attenuate the lipid metabolism disturbance in insulin resistance rats via decreasing SREBP1 expression [16]. However, whether EA can improve PCOS via regulating SREBP1 expression has not been determined, which needs to be expounded.

In this study, for the first time, we evaluated the effect of EA on the abnormally elevated SREBP1 level in a rat model of PCOS-like symptoms and its role in improving insulin resistance, mitochondrial dysfunction and oxidative stress.

\section{Material and methods}

\section{Animal model}

Female Sprague Dawley rats at 4 weeks old were purchased from Chang Sheng biotechnology co., Ltd. (Liaoning, China). The rats were maintained at $25 \pm 1{ }^{\circ} \mathrm{C}$, humidity of $45-55 \%$, under $12 \mathrm{~h}$ light/ $12 \mathrm{~h}$ dark cycles and took food and water freely. There were three experimental groups ( $\mathrm{n}=6$ per group): control, PCOS, PCOS + EA. The rats in PCOS group were received daily hypodermic injection with dehydroepiandrosterone (DHEA, 6 mg/100 g weight, Meilunbio, Dalian, China) for 20 days continuously. While the rats in control group were subcutaneously injected with equivoluminal phosphate buffer solution. The rats in EA + PCOS group were subjected to EA intervention (ST29 and SP6 acupuncture points, $2 \mathrm{~Hz}, 0.8-1.3 \mathrm{~mA}$ ) every other day after the first injection with DHEA. EA was performed for 15 min each time in the first week, $20 \mathrm{~min}$ in the second and third week, and $25 \mathrm{~min}$ in the fourth and fifth week. All rats were killed after the 5-week EA intervention by injection with overdose of pentobarbital sodium. Animals were treated in accordance with Guide for the Care and Use of Laboratory Animals (8th edition, National Academies Press).

\section{Overexpression of SREBP1 in rats}

The recombinant lentivirus containing SREBP1 gene (LV-SREBP1) and negative control lentivirus (LV-NC) were obtained from Wanleibio (Shenyang, China). The rats were intravenously injected with LV-SREBP1 or LV-NC $\left(5 \times 10^{7} \mathrm{TU}\right.$ per rat $)$ once at the first day of DHEA injection.

\section{Inhibition of AMP-activated protein kinase (AMPK) signaling pathway in rats}

To suppress the activation of AMPK signaling pathway in rats, the inhibitor of AMPK pathway compound C (10 mg/kg, MedChemExpress, USA) or equal volume vehicle was intraperitoneally injected into rats at $24 \mathrm{~h}$ before the euthanasia.

\section{HE staining}

The ovarian tissues of rats after receiving the appropriate paraffin-embedding procedure, were cut into $5-\mu \mathrm{m}$ sections using a slicer. Then the sections were subjected to dewaxing, rehydration, and routine HE staining. The images were observed at a magnification of $200 \times$ under a light microscope (Olympus, Japan).

\section{ELISA}

The serum levels of insulin, testosterone, luteinizing hormone (LH), and follicle-stimulating hormone (FSH) were assessed by commercialized ELISA kits (USCN Life Science, Wuhan, China). The contents of insulin, testosterone, $\mathrm{LH}$, and FSH were calculated according to the standard curve.

\section{Immunofluorescence staining}

Immunofluorescence staining was performed to detect the expression of SREBP1 in the ovarian tissues. The $5-\mu \mathrm{m}$ sections of ovarian tissues were put into citrate antigen retrieval solution and heated in the microwave for $10 \mathrm{~min}$. Subsequently, the sections were blocked in goat serum (Solarbio, Beijing, China) for $15 \mathrm{~min}$. Primary 
SREBP1 antibody (1:100, Abcam, UK) was added to sections and incubated at $4{ }^{\circ} \mathrm{C}$ overnight. Then Cy3 labeled secondary antibody (1:200, Beyotime, Haimen, China) was applied at room temperature for $1 \mathrm{~h}$. DAPI solution (Beyotime) was dropped to sections for nuclear counterstaining. The immunofluorescence staining of SREBP1 was observed under a fluorescence microscope (Olympus) at a magnification of $400 \times$.

\section{Primary culture of granulosa cells and treatment}

The primary granulosa cells were isolated from rats as described previously [17]. Briefly, the female SpragueDawley and PCOS-like rats were accepted hypodermic injection with PMSG (15 IU per rat). Then the ovarian tissues were collected from rats under sterile conditions at $48 \mathrm{~h}$ after the injection. After washing with PBS for two times, the granulosa cells were released from the ovarian tissues by puncture using a 26 -gauge needle. Then the collected granulosa cells were cultured in DMEM/F12 medium (Gibco, USA) containing $10 \%$ fetal bovine serum (Hyclone, USA) at $37^{\circ} \mathrm{C}$ with $5 \% \mathrm{CO}_{2}$.

To overexpress SREBP1, the granulosa cells were infected with LV-SREBP1 or LV-NC at multiplicity of infection (MOI) of 20. At $72 \mathrm{~h}$ after the infection, the granulosa cells were subjected to serum starvation for $12 \mathrm{~h}$ and then treated with $100 \mathrm{nM}$ insulin for $5 \mathrm{~min}$. Subsequently, the cells were obtained for further detection.

\section{Real-time PCR}

RNApure Total RNA extraction kit (BioTeke, Beijing, China) was employed for total RNA isolation from the ovarian tissues. Then the total RNA was reverse transcribed using M-MLV reverse transcriptase (Takara Bio, Japan) to obtain cDNA. Real-time PCR was conducted using Taq HS Perfect Mix (Takara Bio) on a Real-Time Quantitative Thermal Block (BIONEER, Korea). The primer sequences are listed in Table 1.

\section{Western blotting}

RIPA lysis buffer (Beyotime) was adopted to acquire protein sample. Then the equal amount protein samples were loaded on $8-12 \%$ polyacrylamide gel for electrophoresis separation, followed by blotting onto a polyvinylidene difluoride membrane (Thermo Fisher Scientific, USA). Blocking was performed by incubation in $5 \%$ bovine serum albumin (BSA, Biosharp, Guangzhou, China) for $1 \mathrm{~h}$. Then the membranes were probed with primary antibodies SREBP1 (1:1000, Proteintech, China), CYP17 (1:500, Proteintech), CYP19 (1:500, Proteintech), AMPKa (1:1000, Cell Signaling Technology, USA), p-AMPK $\alpha$ (1:1000, Cell Signaling Technology), p-AKT (1:2000, Cell Signaling Technology), AKT (1:1000, Cell Signaling Technology), p-IR (1:1000, Cell Signaling
Table 1 Oligonucleotide primer sets for real-time PCR

\begin{tabular}{lll}
\hline Name & Sequence $\left(\mathbf{5}^{\prime} \mathbf{- 3}^{\prime} \mathbf{)}\right.$ & Length \\
\hline CYP17 F & TGGAGGTGATAAAGGGTT & 18 \\
CYP17 R & CGTCAGGCTGGAGATAGA & 18 \\
CYP19 F & GCCTGTCGTGGACTTGGT & 18 \\
CYP19 R & TAAATTCATTGGGCTTGG & 18 \\
SREBP1 F & CGACTACATCCGCTTCTTACA & 21 \\
SREBP1 R & AGGTTTCATGCCCTCCATA & 19 \\
$\beta$-actin F & CCACTGCCGCATCCTCTT & 18 \\
$\beta$-actin R & GGTCTTTACGGATGTCAACG & 20 \\
\hline
\end{tabular}

Technology), insulin receptor $\beta$ (IR, 1:1000, Cell Signaling Technology), cytochrome $C$ (1:1000, Abclonal, China), $\beta$-actin (1:2000, Proteintech) at $4{ }^{\circ} \mathrm{C}$ overnight. Goat antirabbit or anti-mouse IgG (1:10000, Proteintech) was used as secondary antibody. The antigen-antibody complexes were visualized with ECL Plus reagent (7 sea biotech, Shanghai, China).

\section{Detection of mitochondrial complex enzymes}

The mitochondrial complex I, II, III, and IV activities in ovarian granulosa cells were determined with the commercial mitochondrial respiratory chain complex I, II, III, and IV assay kits (Solarbio) according to the manufacturer's instructions.

\section{Mitochondrial membrane potential (MMP)}

The MMP of ovarian granulosa cells was assessed with Mitochondrial Membrane Potential Assay Kit with JC-1 (Solarbio). Briefly, the mitochondria were isolated from ovarian granulosa cells by centrifugation $(12,000 \mathrm{~g}$, $10 \mathrm{~min})$ at $4{ }^{\circ} \mathrm{C}$ twice. Then the isolated mitochondria were stained with $\mathrm{JC}-1$ solution and measured using a fluorescence microplate reader (Tecan, Switzerland).

\section{Measurement of ATPase activity}

The ATPase activity of ovarian granulosa cells was determined using ATP assay kit (Nanjing Jiancheng Bioengineering Institute, China) according to the standard procedure. The result was detected using a microplate reader (BioTek, USA) at $636 \mathrm{~nm}$.

\section{Antioxidant-enzyme activity measurement}

The CAT, SOD, and GPX activities of ovarian granulosa cells were assessed using Catalase (CAT) assay kit, Superoxide Dismutase (SOD) assay kit, and Glutathione Peroxidase (GSH-PX) assay kit following the operation 
manual, respectively. All the commercial kits were purchased from Nanjing Jiancheng Bioengineering Institute.

\section{Reactive oxygen species (ROS) level detection}

The ROS level was determined using a ROS fluorescent probe-DHE (KeyGEN BioTECK, China). The isolated ovarian granulosa cells were washed with PBS, and probed with DHE buffer for $30 \mathrm{~min}$ at $37^{\circ} \mathrm{C}$. To remove the redundant DHE, the cells were washed with PBS for three times. The result was obtained on a flow cytometer (ACEA Biosciences, USA).

\section{Statistical analysis}

All experimental data are expressed as the mean \pm standard deviation. Differences among multiple groups were analyzed by one-way analysis of variance followed by Tukey's multiple comparison test using GraphPad Prism 8 software. $P$ value less than 0.05 was considered to have significant statistical difference.

\section{Results}

\section{Effect of EA treatment on SREBP1 expression in PCOS-like} rats

First, the expression of SREBP1 in ovarian tissues of rats was observed by immunofluorescence staining. As presented in Fig. 1a, SREBP1 expression was obviously enhanced in the ovarian tissues of PCOS-like rats, as compared with control group. Whereas treatment with EA significantly suppressed DHEA-induced SREBP1 expression. Consistently, the mRNA level of SREBP1 in ovarian tissues was more than tripled in PCOS group, which could be remarkably repressed by EA treatment (Fig. 1b). Therefore, EA treatment restrained DHEAinduced the enhanced expression of SREBP1.

\section{EA intervention alleviated PCOS-like symptoms via regulating SREBP1}

Next, we determined whether SREBP1 participated in the beneficial effect of EA against PCOS-like symptoms in rats. To achieve this, lentivirus-mediated overexpression of SREBP1 in PCOS-like rats was performed. As shown in Fig. 2a, EA-induced the reduced protein level of SREBP1 in ovarian tissues was reversed by LV-SREBP1. In addition, the histopathologic changes of ovarian tissues were evaluated by HE staining. DHEA-induced multiple ovarian follicular cysts were relieved by EA intervention, however, overexpression of SREBP1 counteracted the therapeutic effect of EA (Fig. 2b). Moreover, SREBP1 reversed EA-induced increase in FSH level, and decreases in $\mathrm{LH}$, testosterone levels and LH/FSH ratio (Fig. 2c-f). Furthermore, the protein and mRNA levels of CYP17 and CYP19 in ovarian tissues were significantly lowered by EA treatment, which were elevated by

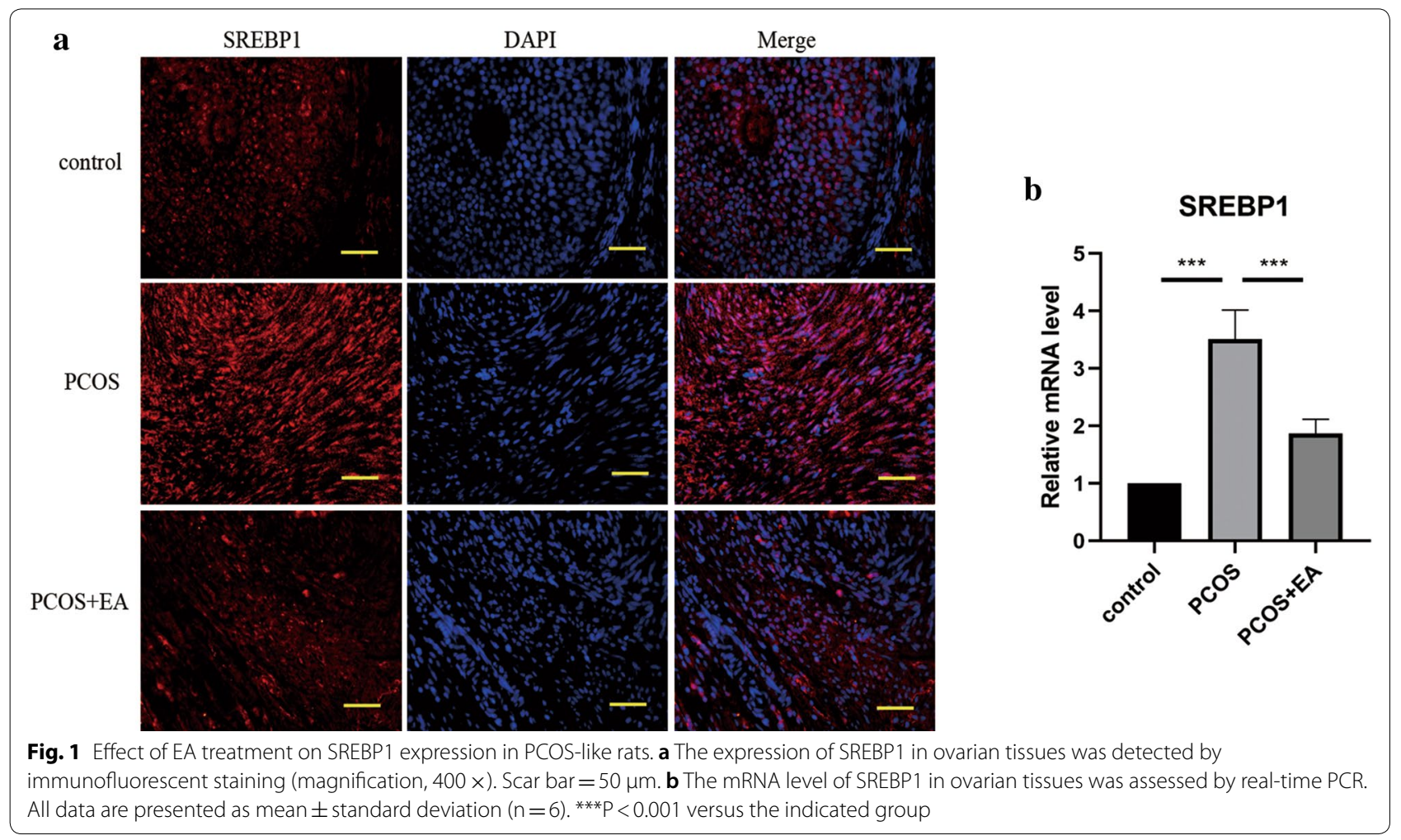




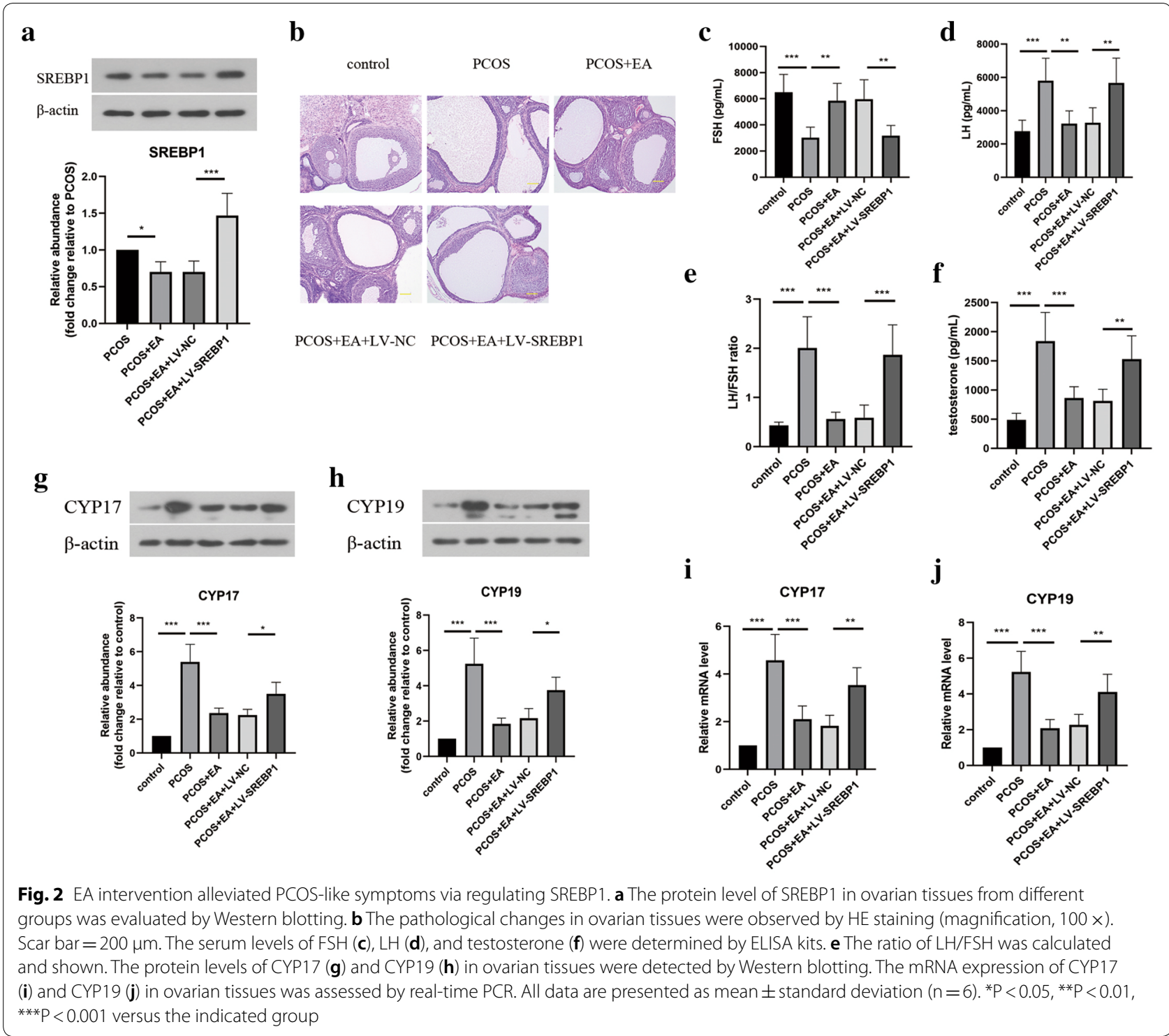

SREBP1 overexpression. These data indicated that overexpression of SREBP1 impaired the beneficial effect of EA on PCOS-like symptoms in rats.

\section{EA intervention restrained insulin resistance through regulating SREBP1 in PCOS-like rats}

Since insulin resistance has been suggested as an important pathogenic mechanism of PCOS, we next evaluated whether SREBP1 was involved in EA-mediated regulation of insulin resistance in PCOS-like rats. As illustrated in Fig. 3a, the insulin level was strikingly reduced in EA treatment group as compared with PCOS group, whereas further overexpression of SREBP1 upregulated the insulin level. Additionally, EA intervention cut down the homeostatic model assessment of insulin resistance (HOMA-IR) index of PCOSlike rats, which was evidently reversed by SREBP1 overexpression. Thus, EA suppressed insulin resistance in PCOS-like rats via regulating SREBP1.

\section{EA regulated SREBP1 expression via AMPK pathway in PCOS-like rats}

To further investigate the regulatory mechanism of EA on SREBP1 expression, we focused on AMPK signaling pathway. As shown in Fig. 4a, PCOS-mediated the inhibition of AMPK phosphorylation in ovarian tissues was remitted by EA treatment. Moreover, the decreased expression of SREBP1 in ovarian tissues induced by 

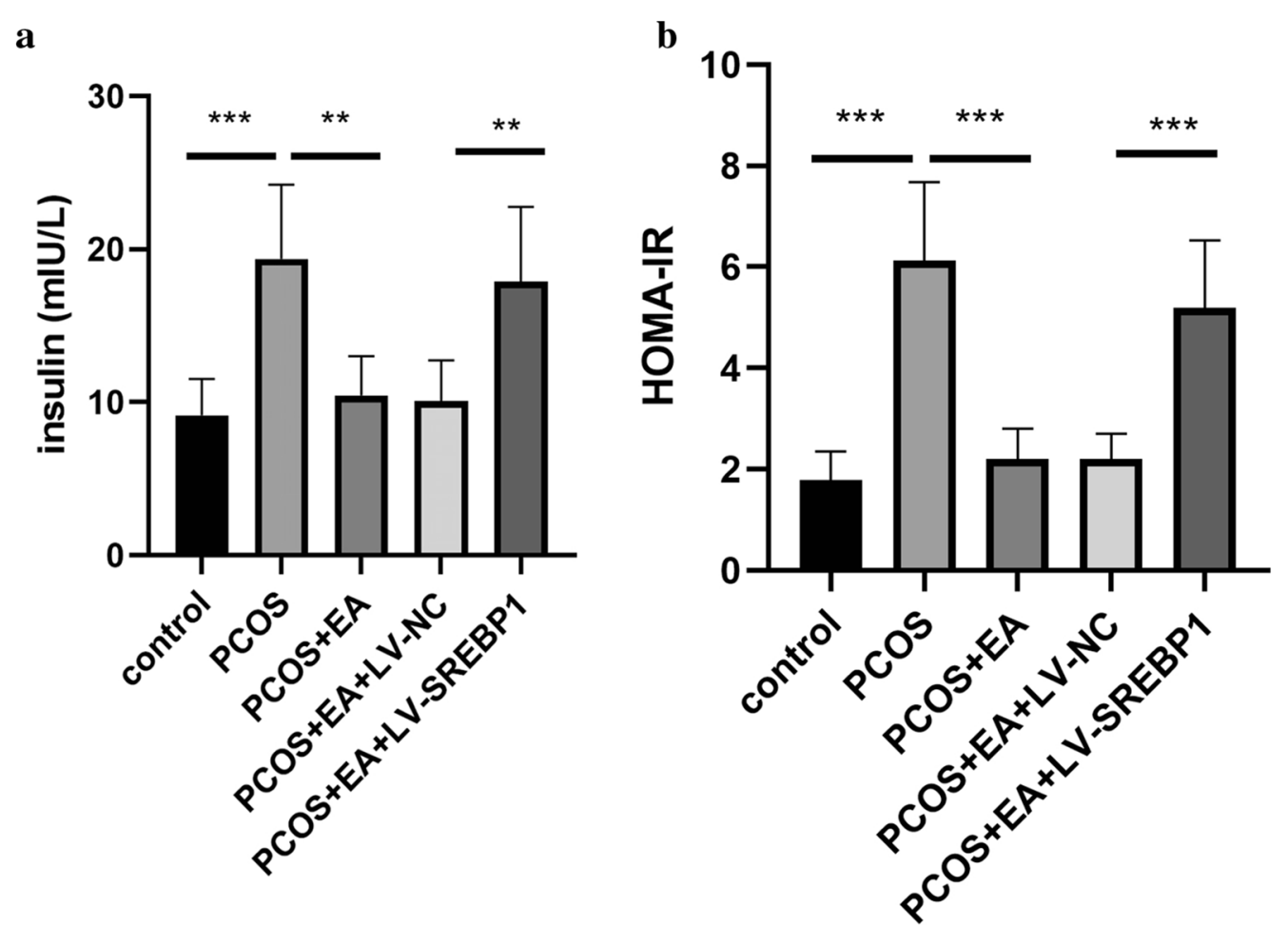

Fig. 3 EA intervention restrained insulin resistance through regulating SREBP1 in PCOS-like rats. a The serum level of insulin was detected by ELISA. b The HOMA-IR index was calculated and shown. All data are presented as mean \pm standard deviation $(n=6)$. ${ }^{* *} P<0.01$, ${ }^{* * *} P<0.001$ versus the indicated group

EA intervention was counteracted by compound $C$, an inhibitor of AMPK pathway. Therefore, EA repressed SREBP1 expression through activating AMPK signaling pathway in PCOS-like rats.

\section{Effect of SREBP1 on insulin pathway in ovarian granulosa cells}

SREBP1 was overexpressed in ovarian granulosa cells by infection with LV-SREBP1. As presented in Fig. 5a and $\mathrm{b}$, a remarkable increase in the phosphorylation of AKT and IR was observed after administration with insulin for $5 \mathrm{~min}$. However, no significant changes were found in ERK and IR protein levels. Overexpression of SREBP1 inhibited AKT and IR phosphorylation induced by insulin.

\section{Effect of SREBP1 on mitochondrial dysfunction in ovarian granulosa cells}

The MMP of granulosa cells was assessed by JC-1 staining and shown in Fig. 6a. The PCOS-like granulosa cells exhibited evident decreased MMP, and overexpression of SREBP1 further enhanced this result. As shown in Fig. 6b-e, SREBP1 overexpression further reduced the decreased complex I, II, III, and IV activities of granulosa cells from PCOS-like ovaries. Furthermore, a significant decrease in ATP activity was observed in PCOSlike granulosa cells, and this change was strengthened by SREBP1 overexpression (Fig. 6f). In addition, the cytochrome $\mathrm{C}$ expression was decreased in the mitochondrion, but increased in the cytoplasm of PCOSlike granulosa cells, which was promoted by enforced expression of SREBP1 (Fig. $6 \mathrm{~g}$ and $\mathrm{h}$ ). These observations suggested that SREBP1 overexpression exacerbated mitochondrial dysfunction in PCOS-like granulosa cells.

\section{Effect of SREBP1 on oxidative stress in ovarian granulosa cells}

To assess the effect of SREBP1 on oxidative stress, the ROS level and activities of GPX, CAT and SOD were detected. As shown in Fig. 7a-d, the ROS level was upregulated, and the CAT, GPX, and SOD activities were declined in PCOS-like granulosa cells. Overexpression of SREBP1 further reinforced the above changes. Thus, SREBP1 overexpression enhanced oxidative stress in PCOS-like granulosa cells. 

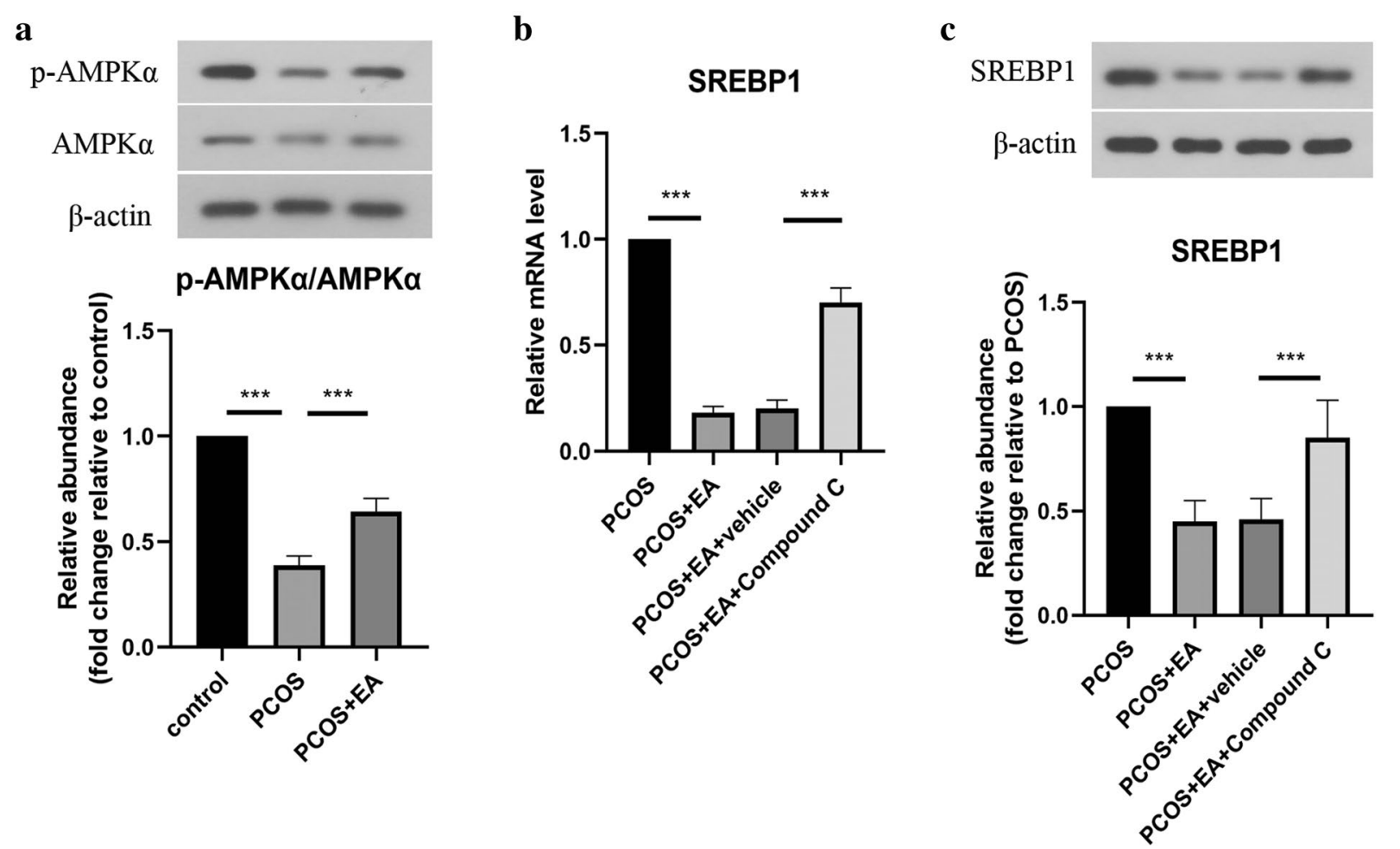

Fig. 4 EA regulated SREBP1 expression via AMPK pathway in PCOS-like rats. a The protein levels of p-AMPKa and AMPKa in ovarian tissues were determined by Western blotting. $\mathbf{b}$ The mRNA expression of SREBP1 in ovarian tissues was assessed by real-time PCR. $\mathbf{c}$ The protein level of SREBP1 in ovarian tissues was evaluated by Western blotting. All data are presented as mean \pm standard deviation $(n=6) .{ }^{* * *} P<0.001$ versus the indicated group

\section{Discussion}

Acupuncture, as an important therapy of traditional Chinese medicine, has been widely used and accepted because of no serious side-effect. For PCOS, acupuncture therapy has been demonstrated to have a confirmed therapeutic effectiveness. However, the precise mechanisms of acupuncture in PCOS are still not very clear. In this study, we mainly focused on the changes in the metabolic aspect of PCOS-like symptoms. Our results showed that EA treatment significantly restrained DHEA-induced SREBP1 expression. Overexpression of SREBP1 weakened the protective effect of EA on PCOS-like rats. Moreover, SREBP1 was involved in the regulation of EA in insulin resistance in PCOS-like rats. Mechanically, EA inhibited SREBP1 expression via activating AMPK signaling pathway in PCOS-like symptoms. SREBP1 overexpression suppressed insulin-stimulated activation of IR and AKT in ovarian granulosa cells. Therefore, our results further clarified the novel mechanisms of EA in PCOS-like symptoms.

It has been reported that the DHEA-PCOS animal model displays the features of human PCOS, including hyperandrogenism, aberrant maturation of ovarian follicles and anovulation [18-20]. Xi et al. confirmed that DHEA-challenged mice suffered whole-body and skeletal muscle insulin resistance, along with dysfunction of mitochondria [21]. In addition, reproductive and metabolic disturbances were found in DHEAinduced PCOS-like rats [22]. Therefore, the DHEA model was selected in this study to investigate EAmediated protection against PCOS-like symptoms in rats. Many animal and human studies have provided some mechanistic evidence for the therapeutic effect of EA on PCOS. For instance, low-frequency EA reversed the epigenetic and transcriptional changes in the adipose tissues of PCOS patients [23]. Insulin sensitivity could be improved by electrical or manual acupuncture by regulating multiple metabolic Genes and signaling pathways in PCOS model [24]. EA could increase whole-body glucose uptake by activating nervous systems of PCOS women [25]. However, a recent study by Wu et al. found that EA treatment did not raise the live births among women with PCOS, suggesting that EA might led to metabolic changes rather that ovary changes [26]. In spite of these studies, the biological function and its detailed mechanisms of EA in PCOS 
a
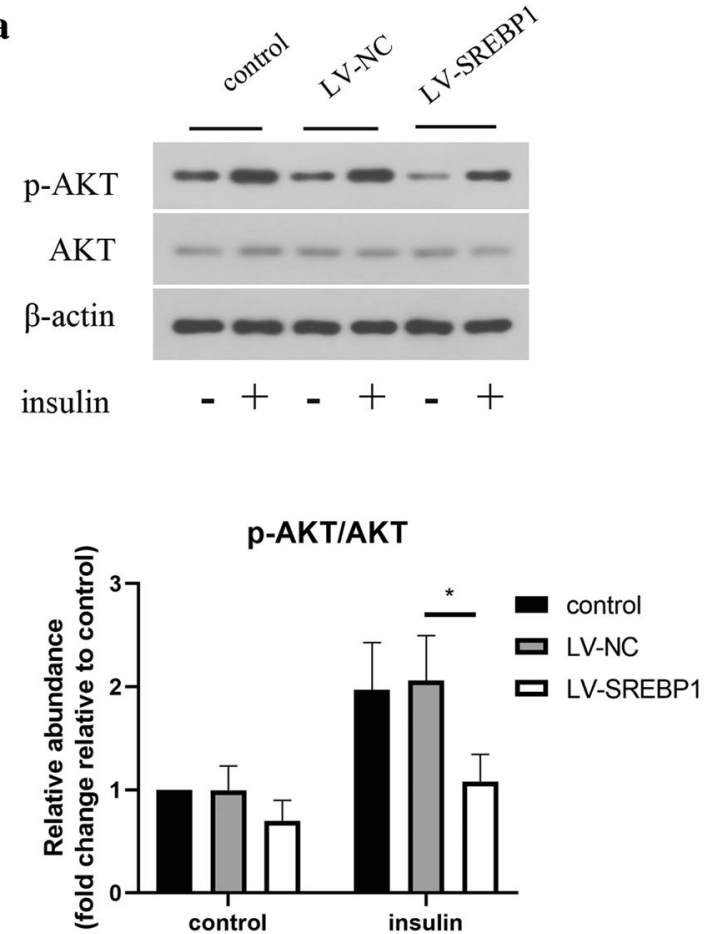

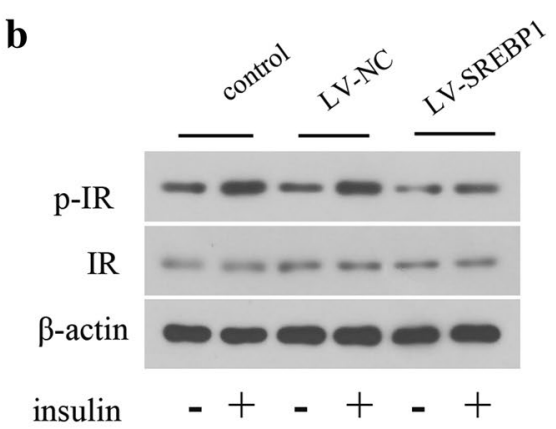

$\mathrm{p}-\mathrm{IR} / \mathrm{IR}$

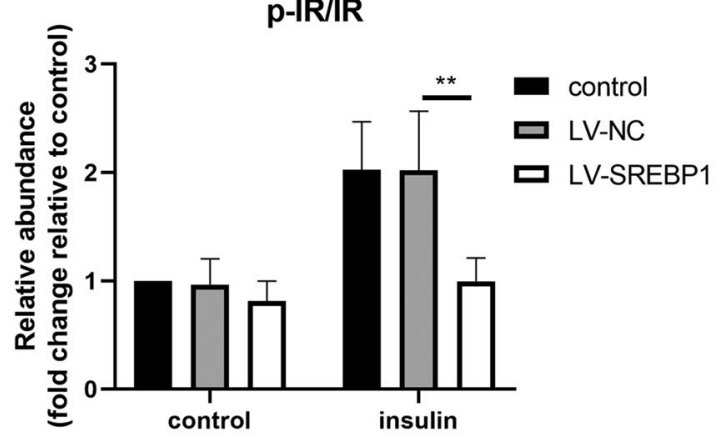

Fig. 5 Effect of SREBP1 on insulin pathway in ovarian granulosa cells. $\mathbf{a}, \mathbf{b}$ The protein levels of p-AKT, AKT, p-IR, and IR in primary ovarian granulosa cells isolated from rats were detected by Western blotting. All data are presented as mean \pm standard deviation $(n=3)$. ${ }^{*} P<0.05$, ${ }^{* *} P<0.01$ versus the indicated group

need to be further investigated. SREBP1 is an important transcription factor for lipid metabolism regulation, which regulates the expression of many genes via binding to their promoter regions. A great deal of studies have demonstrated the aberrant expression of SREBP1 in multiple diseases, such as pancreatic cancer [27], diabetic nephropathy [28], non-alcoholic fatty liver disease [29] and so on. Recent evidence has also suggested that the increased expression of SREBP1 participates in the progression of PCOS $[13,30]$. Consistent with this, our results showed that SREBP1 expression was raised in the ovarian tissues of PCOS-like rats. EA treatment inhibited SREBP1 expression in the ovarian tissues. Thus, inhibition of SREBP1 expression may take part in the therapeutic action of EA on PCOS.

To further evaluate whether EA treatment improved PCOS-like symptoms in rats via regulating SREBP1 expression, we overexpressed SREBP1 in rats by injecting LV-SREBP1. The disorder of sexual hormones has been confirmed to be closely related to the development of PCOS. The upregulated testosterone level indicates hyperandrogenism of PCOS patients [31]. Moreover, the elevated LH/FSH ratio is also a distinguishing hallmark of PCOS, which promotes the arrest of ovarian folliculogenesis [31, 32]. In the present study,
EA intervention-mediated the inhibition in LH/FSH ratio and testosterone level was repressed by SREBP1 overexpression. Besides that, CYP17 and CYP19 are key enzymes in androgen biosynthesis, which were upregulated during the progression of PCOS [33, 34]. In this study, EA treatment suppressed CYP17 and CYP19 expression, which was reversed by SREBP1 overexpression. Therefore, EA treatment improved PCOS-like symptoms via suppressing SREBP1 expression.

Insulin resistance is another characteristic of PCOS, which frequently occurs in obese patients. It has been shown that insulin resistance promotes the production of male hormones, but lowers the level of sex hormone binding globulin, which leads to a dramatical increase in testosterone level in the body [35]. In addition, the increased LH/FSH ratio, testosterone and DHEA levels in PCOS women were caused by insulin resistance [36]. Thus, insulin resistance may cause hyperandrogenemia in PCOS. In the present study, EA treatment ameliorated insulin resistance as evidenced by decreasing serum insulin level and HOMA-IR index in PCOS-like rats, which was counteracted by SREBP1 overexpression. Previous studies also indicated that insulin action could be regulated in granulosa cells [37], and damaged insulin action may affect granulosa cells isolated from 

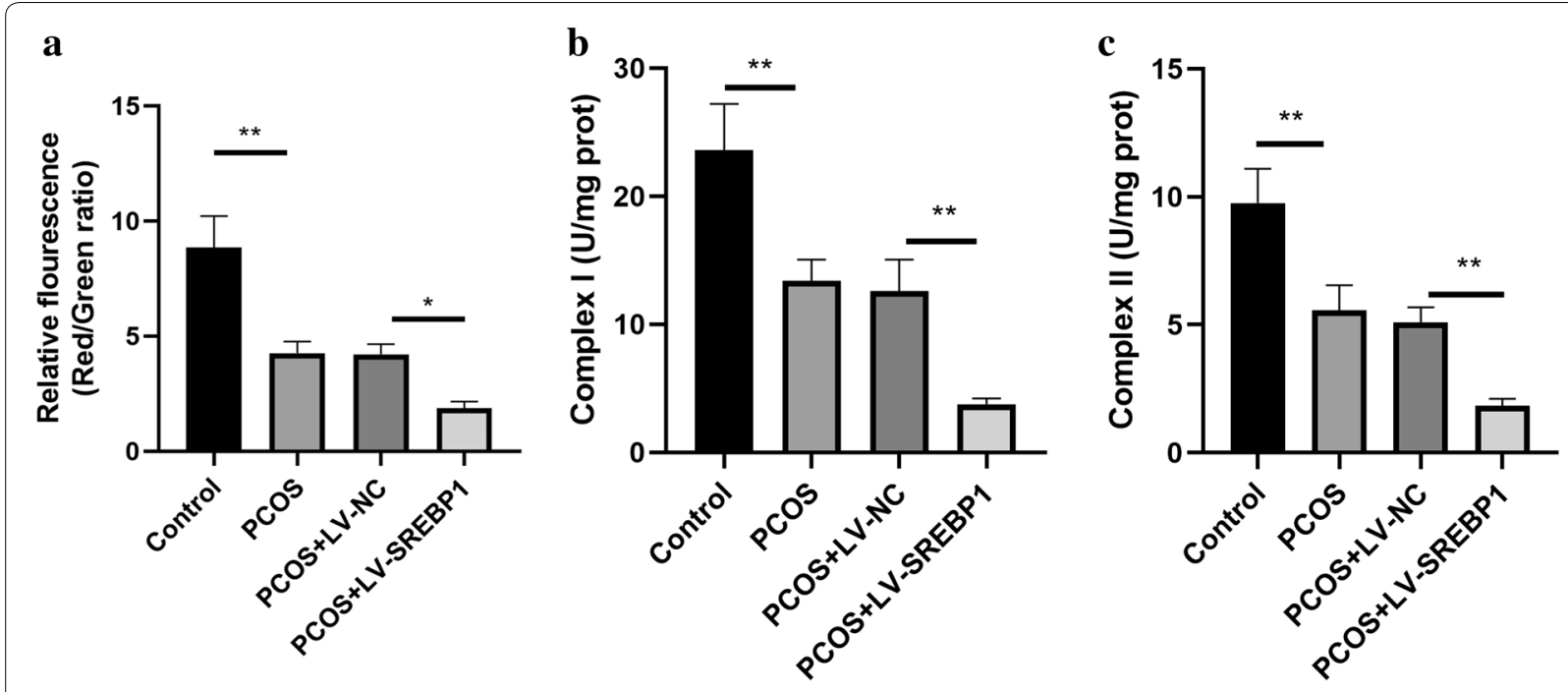

d
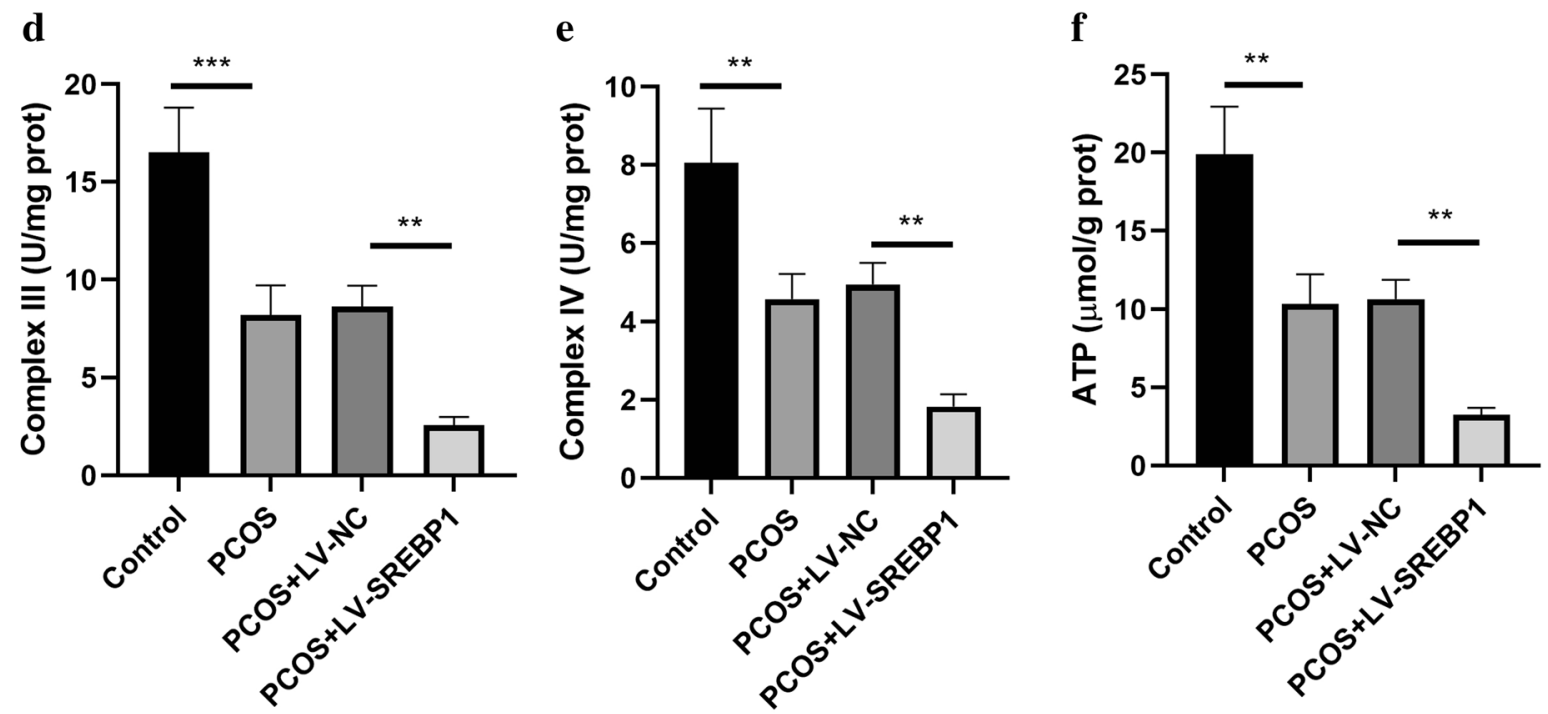

g
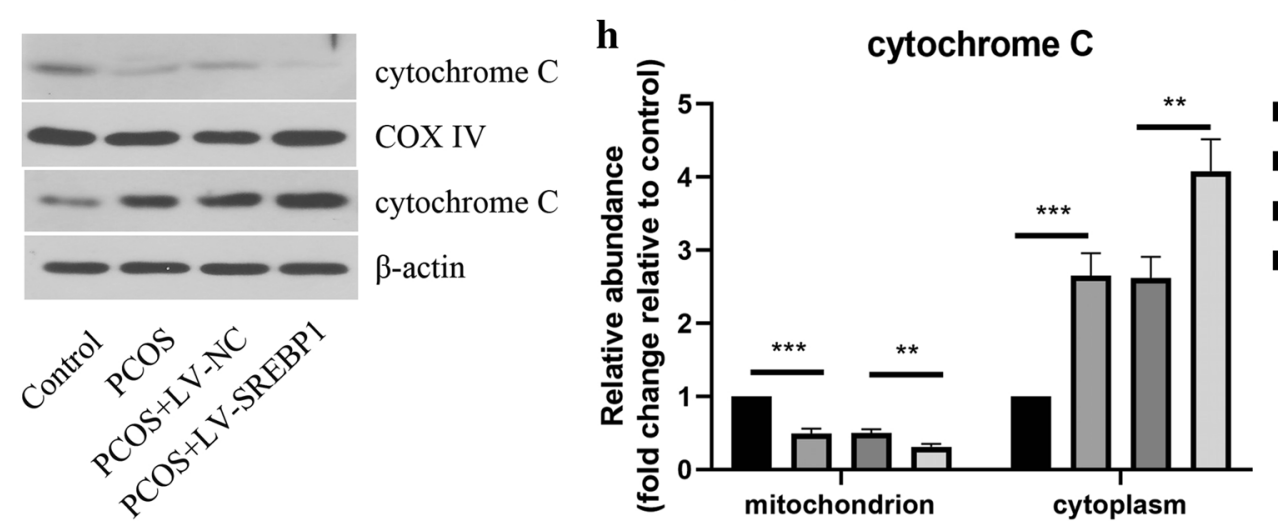

cytochrome C

Fig. 6 Effect of SREBP1 on mitochondrial dysfunction in ovarian granulosa cells. a JC-1 staining was adopted for detecting mitochondrial membrane potential. The activities of Complex I (b), Complex II (c), Complex III (d), Complex IV (e), and ATP (f) in ovarian granulosa cells were detected. $\mathbf{g}, \mathbf{h}$ Western blotting for the protein level of cytochrome $\mathrm{C}$ in mitochondrion and cytoplasm of ovarian granulosa cells. All data are presented as mean \pm standard deviation $(n=3)$. ${ }^{*} P<0.05,{ }^{* *} P<0.01$, ${ }^{* *} P<0.001$ versus the indicated group 
$\mathbf{a}$

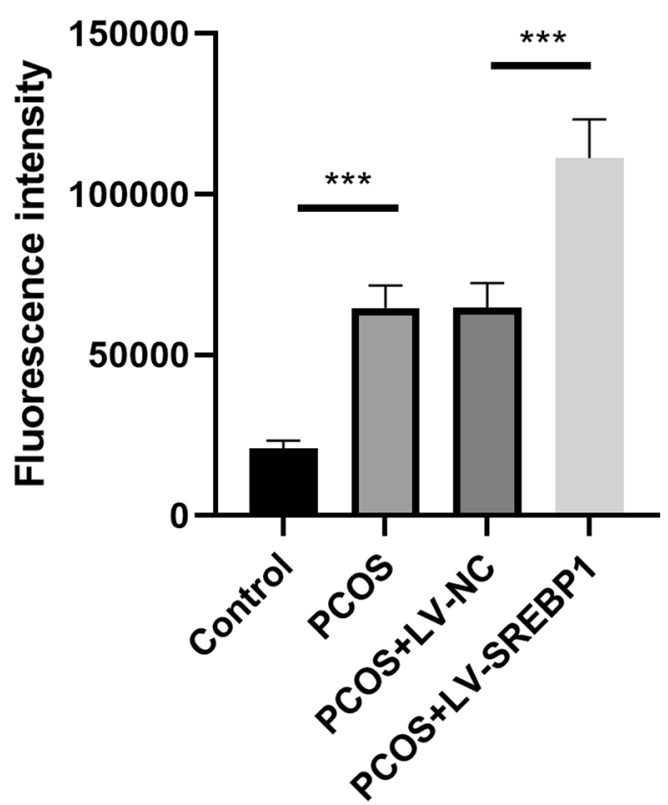

c

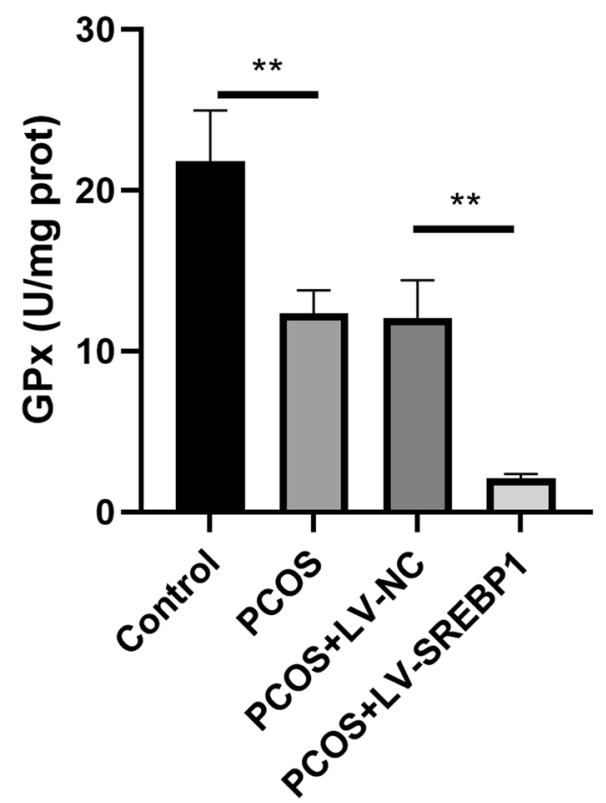

b

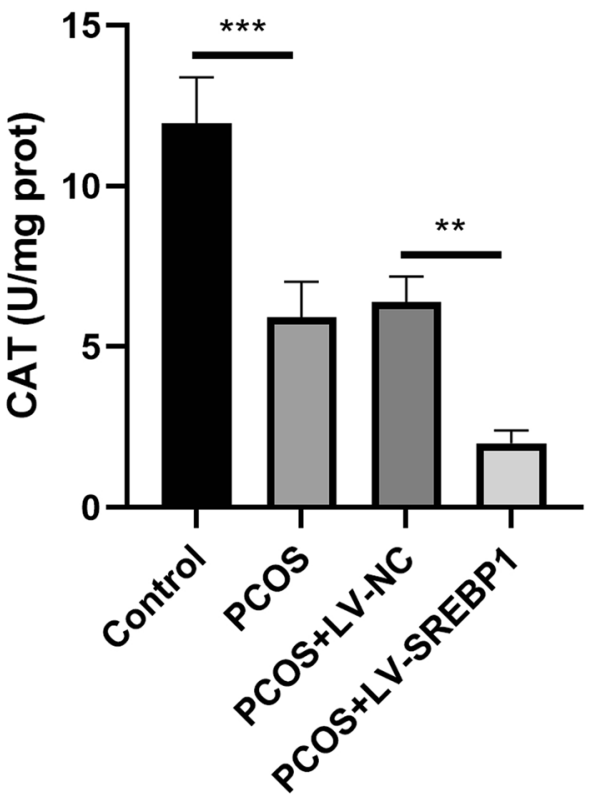

d

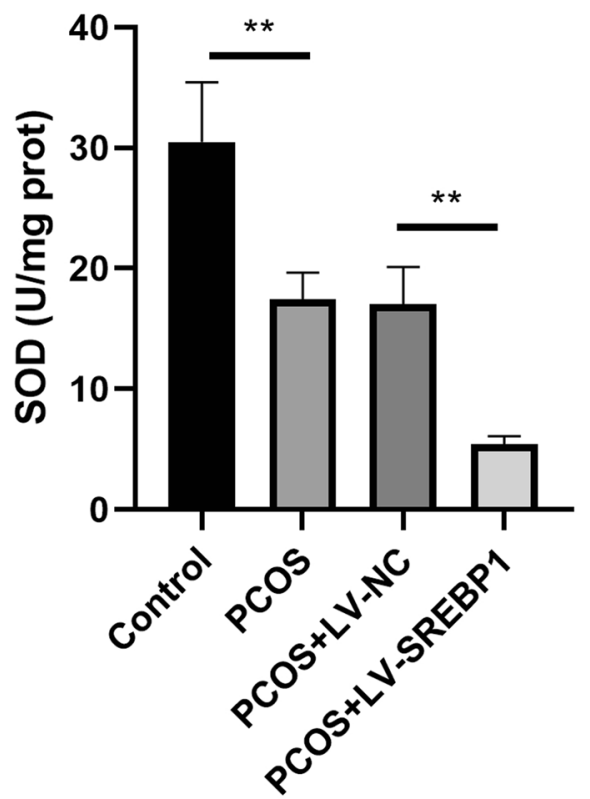

Fig. 7 Effect of SREBP1 on oxidative stress in ovarian granulosa cells. The ROS level (a), and activities of CAT (b), GPX (c), and SOD (d) in ovarian granulosa cells were detected using the commercial kits. All data are presented as mean \pm standard deviation $(n=3)$. ${ }^{*} P<0.01,{ }^{* * *} P<0.001$ versus the indicated group

PCOS rats [38], indicating a close connection between insulin resistance and follicle formation. In normal condition, the released insulin binds to the insulin receptor and subsequently activates the phosphorylation of multiple downstream proteins, including IR and AKT [39].
Our data demonstrated that overexpression of SREBP1 restrained insulin-induced IR and AKT phosphorylation. These findings suggested that regulation of SREBP1 was involved in the protective mechanism of EA against insulin resistance in PCOS-like symptoms. 
AMPK is recognized as an energy sensor that regulates fatty acid and cholesterol synthesis. Beyond that, AMPK also has been found to play pivotal roles in reproduction. A previous study has indicated that AMPK participates in the regulation of steroidogenesis in granulosa cells. Shabnam et al. suggested that activation of AMPK regulated steroidogenesis in granulosa cells from PCOS rats [40]. Moreover, growing evidence demonstrated that SREBP1, as a downstream molecule, regulated by AMPK [41-43]. In this study, we found that EA intervention facilitated the activation of AMPK pathway in PCOS-like rats. EA-induced inhibition of SREBP1 expression was repressed by AMPK inhibitor. Thus, EA treatment inhibited SREBP1 expression through activating AMPK pathway in PCOS-like symptoms.

Increasing evidence has indicated that mitochondrial dysfunction participates in the pathogenesis of PCOS. It has been confirmed that mitochondrial dysfunction is closed related with the pathological features of PCOS, including insulin resistance and hyperandrogenism [44]. Since mitochondrial function is critical for energy supply, the disorder of mitochondria may lead to reduced production of ATP [45]. Moreover, mitochondrial dysfunction results in excessive ROS production, which causes oxidative stress, another important pathogenesis of PCOS [46]. Typically, the activities of antioxidant enzymes such as SOD, CAT and GPX have been verified to be decreased in PCOS model [47]. Consistent with these observations, in this study the mitochondrial dysfunction and oxidative stress were found in PCOSlike granulosa cells, which were further aggravated by SREBP1 overexpression. Therefore, SREBP1 participated in mitochondrial dysfunction and oxidative stress during the progression of PCOS.

We realized that there are some limitations in our study. The changes in downstream receptors may be attributed to metabolic or neural origin cardiovascular disturbances of PCOS, which have not been elucidated in this study. In the future study, we will focus on these issues, which can more comprehensively understand the mechanisms of EA.

\section{Conclusions}

This research suggests that EA intervention attenuates hyperandrogenemia, insulin resistance, mitochondrial dysfunction and oxidative stress in PCOS-like model via inhibiting the expression of lipid metabolism regulator SREBP1. AMPK pathway is activated by EA, which participates in the regulation of SREBP1. Our results shed new light on the protective mechanisms of EA for the PCOS treatment.
Abbreviations

PCOS: Polycystic ovary syndrome; EA: Electroacupuncture; DHEA: Dehydroepiandrosterone; SREBP1: Sterol regulatory element binding protein-1; IR: Insulin receptor $\beta$; AMPK: AMP-activated protein kinase; LH: Luteinizing hormone; FSH: Follicle-stimulating hormone; MOI: Multiplicity of infection.

\section{Acknowledgements \\ Not applicable.}

\section{Authors' contributions}

YP, XY, and LG were involved in the conception and design of the research, collected data, performed the statistical analysis, drafted and revised the manuscript. XL, CL, XC, and HW contributed to acquisition, analysis, or interpretation of data for the work. All authors read and approved the final manuscript.

\section{Funding}

This study was funded by grants from the National Natural Science Foundation of China (Nos. 81704114 and 81602272), the Postdoctoral Science

Foundation of China (No. 2018M640315), the Project of Excellent Innovation Talents by Heilongjiang University of Chinese Medicine (No. 2018RCD26), and the Postdoctoral Funding Project of Heilongjiang Provincial Government (No. $\mathrm{LBH}-\mathrm{Z} 18272)$.

\section{Availability of data and materials}

The datasets used or analyzed during the current study are available from the corresponding author on reasonable request.

\section{Ethics approval and consent to participate}

All animal experiments were approved by the ethics committee of Heilongjiang University of Chinese Medicine (SCXK 2018-003).

\section{Consent for publication}

Not applicable.

\section{Competing interests}

The authors declare that they have no competing interests.

\section{Author details}

${ }^{1}$ Disease Prevention Center, The First Affiliated Hospital, Heilongjiang University of Chinese Medicine, Harbin 150040, People's Republic of China. ${ }^{2}$ Department of Obstetrics and Gynecology, The First Affiliated Hospital, Heilongjiang University of Chinese Medicine, Harbin 150040, People's Republic of China.

${ }^{3}$ College of Basic Medicine Sciences, Heilongjiang University of Chinese Medicine, Harbin 150040, People's Republic of China. ${ }^{4}$ Document Retrival Center, Heilongjiang University of Chinese Medicine, Harbin 150040, People's Republic of China. ${ }^{5}$ Department of Gynecological Oncology, Cancer Hospital of Harbin Medical University, Harbin 150081, People's Republic of China.

Received: 24 April 2020 Accepted: 15 October 2020

Published online: 27 October 2020

\section{References}

1. Xie Q, Xiong X, Xiao N, He K, Chen M, Peng J, Su X, Mei H, Dai Y, Wei D, Lin G, Cheng L. Mesenchymal Stem Cells Alleviate DHEA-Induced Polycystic Ovary Syndrome (PCOS) by inhibiting inflammation in mice. Stem Cells Int. 2019;2019:9782373.

2. March WA, Moore VM, Willson KJ, Phillips DI, Norman RJ, Davies MJ. The prevalence of polycystic ovary syndrome in a community sample assessed under contrasting diagnostic criteria. Hum Reprod. 2010;25:544-51.

3. Moghetti P. Insulin resistance and polycystic ovary syndrome. CurrPharm Des. 2016;22:5526-34.

4. Wang J, Wu D, Guo H, Li M. Hyperandrogenemia and insulin resistance: The chief culprit of polycystic ovary syndrome. Life Sci. 2019;236:116940.

5. Shah D, Rasool S. Polycystic ovary syndrome and metabolic syndrome: the worrisome twosome? Climacteric. 2016;19:7-16.

6. Anwar S, Shikalgar N. Prevention of type 2 diabetes mellitus in polycystic ovary syndrome: a review. Diabetes MetabSyndr. 2017;11(Suppl 2):5913-7. 
7. Baldani DP, Skrgatic L, Ougouag R, Kasum M. The cardiometabolic effect of current management of polycystic ovary syndrome: strategies of prevention and treatment. Gynecol Endocrinol. 2018;34:87-91.

8. Johansson J, Stener-Victorin E. Polycystic ovary syndrome: effect and mechanisms of acupuncture for ovulation induction. Evid Based Complement Alternat Med. 2013;2013:762615.

9. Witt CM, Pach D, Brinkhaus B, Wruck K, Tag B, Mank S, Willich SN . Safety of acupuncture: results of a prospective observational study with 229,230 patients and introduction of a medical information and consent form. Forsch Komplementmed. 2009;16:91-7.

10. Stener-Victorin E, Lundeberg T, Waldenstrom U, Manni L, Aloe L, Gunnarsson S, Janson PO. Effects of electro-acupuncture on nerve growth factor and ovarian morphology in rats with experimentally induced polycystic ovaries. Biol Reprod. 2000;63:1497-503.

11. Stener-Victorin E, Lundeberg T, Waldenstrom U, Bileviciute-Ljungar I, Janson PO. Effects of electro-acupuncture on corticotropin-releasing factor in rats with experimentally-induced polycystic ovaries. Neuropeptides. 2001;35:227-31.

12. Shafiee MN, Mongan N, Seedhouse C, Chapman C, Deen S, Abu J, Atiomo W. Sterol regulatory element binding protein-1 (SREBP1) gene expression is similarly increased in polycystic ovary syndrome and endometrial cancer. Acta Obstet Gynecol Scand. 2017;96:556-62.

13. Wang Y, He J, Yang J. Eicosapentaenoic acid improves polycystic ovary syndrome in rats via Sterol Regulatory Element-Binding Protein 1 (SREBP-1)/Toll-Like Receptor 4 (TLR4) pathway. Med SciMonit. 2018;24:2091-7.

14. Liu HW, Wei CC, Chen YJ, Chen YA, Chang SJ. Flavanol-rich lychee fruit extract alleviates diet-induced insulin resistance via suppressing mTOR/SREBP-1 mediated lipogenesis in liver and restoring insulin signaling in skeletal muscle. Mol Nutr Food Res. 2016;60:2288-96.

15. Wu W, Bi Y, Tangsun Y, Yin W, Chen Y, Zhu D. Effects of transcription factor sterol regulatory element binding protein-1c in palmitate acidinduced L6 cells insulin resistance and its mechanism. Zhonghua Yi Xue Za Zhi. 2015;95:611-5.

16. Li ZX, Zhang HH, Lan DC, Zhang HT, Chen XZ, Sun J. Effect of eletroacupuncture intervention on insulin resistance, lipid metabolic disorder and expression of hepatic SREBP-1 $\mathrm{c}$ and fatty acid synthase proteins in rats with hyperlipidemia. J Zhen Ci Yan Jiu. 2018;43:8-13.

17. Chen JJ, Wang SW, Chien EJ, Wang PS. Direct effect of propylthiouracil on progesterone release in rat granulosa cells. Br J Pharmacol. 2003;139:1564-70.

18. Anderson E, Lee MT, Lee GY. Cystogenesis of the ovarian antral follicle of the rat: ultrastructural changes and hormonal profile following the administration of dehydroepiandrosterone. Anat Rec. 1992;234:359-82.

19. Lee GY, Croop JM, Anderson E. Multidrug resistance gene expression correlates with progesterone production in dehydroepiandrosteroneinduced polycystic and equine chorionic gonadotropin-stimulated ovaries of prepubertal rats. Biol Reprod. 1998;58:330-7.

20. Luchetti CG, Solano ME, Sander V, Arcos ML, Gonzalez C, Di Girolamo G, Chiocchio S, Cremaschi G, Motta AB. Effects of dehydroepiandrosterone on ovarian cystogenesis and immune function. J Reprod Immunol. 2004;64:59-74.

21. Song X, Shen Q, Fan L, Yu Q, Jia X, Sun Y, Bai W, Kang J. Dehydroepiandrosterone-induced activation of $\mathrm{MTORC} 1$ and inhibition of autophagy contribute to skeletal muscle insulin resistance in a mouse model of polycystic ovary syndrome. Oncotarget. 2018;9:11905-21.

22. Yu J, Zhai D, Hao L, Zhang D, Bai L, Cai Z, Yu C. Cryptotanshinone reverses reproductive and metabolic disturbances in PCOS model rats via regulating the expression of CYP17 and AR. Evid Based Complement Alternat Med. 2014;2014:670743.

23. Kokosar M, Benrick A, Perfilyev A, Nilsson E, Kallman T, Ohlsson C, Ling C, Stener-Victorin E. A single bout of electroacupuncture remodels epigenetic and transcriptional changes in adipose tissue in polycystic ovary syndrome. Sci Rep. 2018;8:1878.

24. Benrick A, Maliqueo M, Johansson J, Sun M, Wu X, Manneras-Holm L, Stener-Victorin E. Enhanced insulin sensitivity and acute regulation of metabolic genes and signaling pathways after a single electrical or manual acupuncture session in female insulin-resistant rats. Acta Diabetol. 2014;51:963-72.

25. Benrick A, Kokosar M, Hu M, Larsson M, Maliqueo M, Marcondes RR, Soligo M, Protto V, Jerlhag E, Sazonova A, Behre CJ, Hojlund K, Thoren
P, Stener-Victorin E. Autonomic nervous system activation mediates the increase in whole-body glucose uptake in response to electroacupuncture. FASEB J. 2017;31:3288-97.

26. Wu XK, Stener-Victorin E, Kuang HY, Ma HL, Gao JS, Xie LZ, Hou LH, Hu ZX, Shao XG, Ge J, Zhang JF, Xue HY, Xu XF, Liang RN, Ma HX, Yang HW, Li WL, Huang DM, Sun Y, Hao CF, Du SM, Yang ZW, Wang X, Yan Y, Chen XH, Fu P, Ding CF, Gao YQ, Zhou ZM, Wang CC, Wu TX, Liu JP, Ng EHY, Legro RS, Zhang H. Effect of acupuncture and Clomiphene in Chinese women with polycystic ovary syndrome: a randomized clinical trial. JAMA. 2017;317:2502-14.

27. Sun Y, He W, Luo M, Zhou Y, Chang G, Ren W, Wu K, Li X, Shen J, Zhao X, Hu Y. SREBP1 regulates tumorigenesis and prognosis of pancreatic cancer through targeting lipid metabolism. Tumour Biol. 2015;36:4133-41.

28. Bhaskaragoud G, Geetha V, Sharanappa T, Mohan Kumar AS, Hema Kumar C, Suresh KG. Hypolipidemic and antioxidant properties of oryzanol concentrate in reducing diabetic nephropathy via SREBP1downregulation rather than beta-oxidation. Mol Nutr Food Res. 2018;62:e1700511.

29. Quan HY, Kim DY, Kim SJ, Jo HK, Kim GW, Chung SH. Betulinic acid alleviates non-alcoholic fatty liver by inhibiting SREBP1 activity via the AMPK-mTOR-SREBP signaling pathway. Biochem Pharmacol. 2013:85:1330-40.

30. Jiang J, Gao S, Zhang Y. Therapeutic effects of dimethyldiguanide combined with clomifene citrate in the treatment of polycystic ovary syndrome. Rev Assoc Med Bras. 1992;2019(65):1144-50.

31. Chen MJ, Ho HN. Hepatic manifestations of women with polycystic ovary syndrome. Best Pract Res Clin Obstet Gynaecol. 2016;37:119-28.

32. Legro RS, Arslanian SA, Ehrmann DA, Hoeger KM, Murad MH, Pasquali R, Welt CK. Diagnosis and treatment of polycystic ovary syndrome: an Endocrine Society clinical practice guideline. J Clin Endocrinol Metab. 2013:98:4565-92.

33. Hoang YD, McTavish KJ, Chang RJ, Shimasaki S. Paracrine regulation of theca androgen production by granulosa cells in the ovary. Fertil Steril. 2013;100:561-7.

34. Kauffman AS, Thackray VG, Ryan GE, Tolson KP, Glidewell-Kenney CA, Semaan SJ, Poling MC, Iwata N, Breen KM, Duleba AJ, Stener-Victorin E, Shimasaki S, Webster NJ, Mellon PL. A novel letrozole model recapitulates both the reproductive and metabolic phenotypes of polycystic ovary syndrome in female mice. BiolReprod. 2015;93:69.

35. Sorensen AE, Udesen PB, Wissing ML, Englund ALM, Dalgaard LT. MicroRNAs related to androgen metabolism and polycystic ovary syndrome. Chem Biol Interact. 2016;259:8-16.

36. Lagana AS, Rossetti P, Buscema M, La Vignera S, Condorelli RA, Gullo G, Granese R, Triolo O. Metabolism and ovarian function in PCOS women: a therapeutic approach with inositols. Int J Endocrinol. 2016;2016:6306410.

37. Hackbart KS, Cunha PM, Meyer RK, Wiltbank MC. Effect of glucocorticoid-induced insulin resistance on follicle development and ovulation. Biol Reprod. 2013;88:153.

38. Belani M, Purohit N, Pillai P, Gupta S. Modulation of steroidogenic pathway in rat granulosa cells with subclinical $\mathrm{Cd}$ exposure and insulin resistance: an impact on female fertility. Biomed Res Int. 2014:2014:460251.

39. Hao M, Yuan F, Jin C, Zhou Z, Cao Q, Xu L, Wang G, Huang H, Yang D, Xie M, Zhao X. Overexpression of Lnk in the ovaries is involved in insulin resistance in women with polycystic ovary syndrome. Endocrinology. 2016;157:3709-18.

40. Bakhshalizadeh S, Amidi F, Shirazi R, Shabani NM. Vitamin D3 regulates steroidogenesis in granulosa cells through AMP-activated protein kinase (AMPK) activation in a mouse model of polycystic ovary syndrome. Cell Biochem Funct. 2018;36:183-93.

41. Lin YC, Wu MS, Lin YF, Chen CR, Chen CY, Chen CJ, Shen CC, Chen KC, Peng CC. Nifedipine Modulates Renal Lipogenesis via the AMPK-SREBP Transcriptional Pathway. Int J Mol Sci. 2019:20:1570.

42. Lu J, Cong T, Wen X, Li X, Du D, He G, Jiang X. Salicylic acid treats acne vulgaris by suppressing AMPK/SREBP1 pathway in sebocytes. Exp Dermatol. 2019;28:786-94.

43. Liu G, Kuang S, Cao R, Wang J, Peng Q, Sun C. Sorafenib kills liver cancer cells by disrupting SCD1-mediated synthesis of monounsaturated fatty acids via the ATP-AMPK-mTOR-SREBP1 signaling pathway. FASEB J. 2019;33:10089-103. 
44. Shukla P, Mukherjee S. Mitochondrial dysfunction: An emerging link in the pathophysiology of polycystic ovary syndrome. Mitochondrion. 2020;52:24-39.

45. Zhou B, Tian R. Mitochondrial dysfunction in pathophysiology of heart failure. J Clin Invest. 2018;128:3716-26.

46. Zhang Y, Zhao W, Xu H, Hu M, Guo X, Jia W, Liu G, Li J, Cui P, Lager S, Sferruzzi-Perri AN, Li W, Wu XK, Han Y, Brannstrom M, Shao LR, Billig H. Hyperandrogenism and insulin resistance-induced fetal loss: evidence for placental mitochondrial abnormalities and elevated reactive oxygen species production in pregnant rats that mimic the clinical features of polycystic ovary syndrome. J Physiol. 2019;597:3927-50.
47. Hong $Y$, Yin $Y$, Tan $Y$, Hong $K$, Zhou $H$. The flavanone, naringenin, modifies antioxidant and steroidogenic enzyme activity in a rat model of letrozoleinduced polycystic ovary syndrome. Med SciMonit. 2019;25:395-401.

\section{Publisher's Note}

Springer Nature remains neutral with regard to jurisdictional claims in published maps and institutional affiliations.
Ready to submit your research? Choose BMC and benefit from:

- fast, convenient online submission

- thorough peer review by experienced researchers in your field

- rapid publication on acceptance

- support for research data, including large and complex data types

- gold Open Access which fosters wider collaboration and increased citations

- maximum visibility for your research: over $100 \mathrm{M}$ website views per year

At BMC, research is always in progress.

Learn more biomedcentral.com/submissions 